\title{
Picosecond Laser Induced Colour Centres: Stress-free Markings and Choice of Guiding Optics
}

\author{
Andreas LEMKE, David ASHKENASI \\ ${ }^{* 1}$ Laser- and Medical- Technology Berlin GmbH (LMTB), Applied Laser Technology, \\ Fabeckstr. 60-62, 14195 Berlin, Germany \\ E-mail: a.lemke@lmtb.de
}

\begin{abstract}
It is known that ionising radiation (X-ray, gamma rays, electrons) can induce numerous changes in the physical properties of glasses. The most obvious effect is visible colouration, which is caused by the accumulation of colour centres (defects) in the irradiated volume. The application of such induced colour centres has prompted a renewed interest since they can be generated and bleached reversibly. We present results on laser induced colour centres in different types of glasses using picosecond laser pulses. For example, an unexpectedly low peak intensity threshold of $4 * 10^{14} \mathrm{~W} / \mathrm{m}^{2}$ for the laser induced colouring in BK7 glass is observed at a wavelength of $355 \mathrm{~nm}$ and a pulse width of $6 \mathrm{ps}$. A strong absorption of laser induced colour centres between 330 and $800 \mathrm{~nm}$ for BK7 is shown. Picosecond laser pulses at a longer wavelength of $532 \mathrm{~nm}$ and even $1064 \mathrm{~nm}$ induce colour centres in many different glasses, making marking application more feasible. By applying different focusing optics the influence of changing focal length and energy flux density on the volume colouring effect have been analysed. The changes in the optical transmission compared to the unperturbed state are significant. Non-linear optical effects and possible implications for future optics guiding ultra-short laser pulses are addressed.
\end{abstract}

DOI:10.2961/jlmn.2011.01.0019

Keywords: ultra short laser pulses, defect formation, colouring and damage thresholds, marking

\section{Introduction}

In recent years the advantages of ultra-short laser pulses (USLP) were utilized to induce changes in the optical properties of transparent materials [1-6]. In most cases induced modifications are related to density changes in the silicate glass matrix.

The generally accepted mechanism for the excitation of dielectrics for the interaction of USLP with the glass matrix is multi-photon enhanced avalanche absorption and the dynamic energy transfer from the "hot" electronic system into the lattice by electron-phonon coupling [7-9] to finally reach a temperature equilibrium between both. The absorption probability depends on the optical properties and initial conditions. Most noticeable modifications inside the material, density changes and micro cracks, are the results from subsequent heating after laser excitation.

In addition to (stress-related) density changes, laser-induced volume "browning" of glasses has been reported [10-14], which alone show no indication of mechanical stress inside the bulk. After femtosecond laser pulse excitation, alternative relaxation channels seem to yield an accumulation of defects altering the transmission properties of glass. This „browning effect“ can remain stable for years. The browning effect, caused by an accumulation of colour centres, is also known from strong ionizing radiation $[15,16]$. This method can be used to introduce practically stress-free internal markings, which do not influence the mechanical stability of the material. Currently used ablation methods do not provide this ability.

In this study, picosecond laser excitation at 355 , 532 and $1064 \mathrm{~nm}$ wavelengths was introduced to evaluate the possible generation of colour centres in commonly used technical glasses such as BK7 or soda-lime (Optiwhite $\left.{ }^{\circledR}\right)$.

\section{Experiment}

The experimental studies with picosecond laser pulses were performed with a DPSSL oscillator and amplifier system (Lumera Laser "Rapid"). The experiments were conducted at three different wavelengths: the fundamental $1064 \mathrm{~nm}(10 \mathrm{ps})$, the second $532 \mathrm{~nm}(7 \mathrm{ps})$, and third harmonic at $355 \mathrm{~nm}(6 \mathrm{ps})$. Maximum single pulse energies at all three wavelengths are available at $10 \mathrm{kHz}$, however, average power is optimized at higher repetition rates. Two different scanner systems (Scanlab) were implemented in the picosecond laser study: 1. An IntelliScan system for 1064 and $532 \mathrm{~nm}$ with individual F-Theta lenses for each wavelength, both having a focal length of $80 \mathrm{~mm}$; 2. a HurryScan for $355 \mathrm{~nm}$ with a F-Theta lens of $103 \mathrm{~mm}$. The laser spot size equals ca. $25 \mu \mathrm{m}$ for the $1064 \mathrm{~nm}$ and ca. $20 \mu \mathrm{m}$ for the 532 and $355 \mathrm{~nm}$ picosecond laser beam. The scanning motion characterizes a grating. The scanning velocity was adjusted for the higher repetition rates. The experimental set-up was prepared for spectral monitoring, however, in the peak power range $<4 \mathrm{MW}$ available with the picosecond laser system (i.e. pulse energy $<40 \mu \mathrm{J}$ at $1064 \mathrm{~nm}$ ), no white-light was observed for the three wavelengths and glass samples, soda lime and BK7, selected for this study. This result is accentuated, because for fs-pulse propagation through the studied samples, the typical signature of white-light generation was observed even at modest single pulse energies $E=10 \mu \mathrm{J}[13,14]$. 


\section{Results}

The threshold for visible glass colouring is depending on wavelength and material. Using picosecond laser pulses at 1064 and $532 \mathrm{~nm}$ a threshold for the browning with respect to the single pulse energy can be identified. Below this threshold no browning inside the material was observed. With $355 \mathrm{~nm}$ USLP a browning with large track length was observed in different glasses at single pulse energies considerably below $1 \mu \mathrm{J}$. Fig. 1 shows the depth extension of the browning at three different wavelengths for a soda-lime glass.

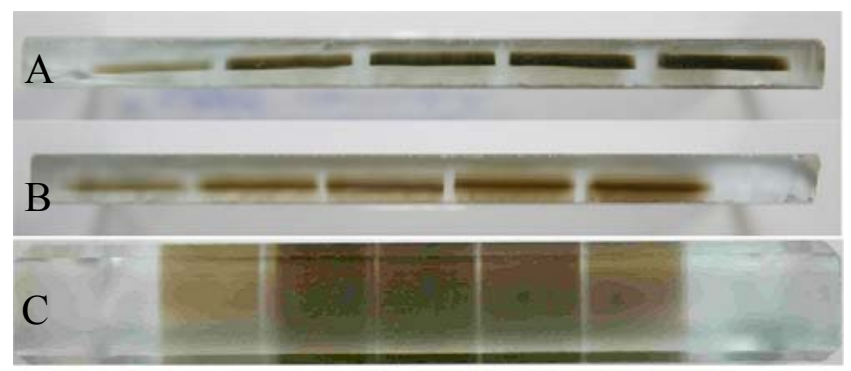

Fig. 1: Side edge view on soda-lime samples (Optiwhite $\AA$ ) after laser induced browning. The laser beam crossed the samples from bottom to top. A+B: $4 \mathrm{~mm}$ glass depth, scanning speed $=$ $250 \mathrm{~mm} / \mathrm{s}$, Number of cycles left to right $1 \mathrm{x}, 5 \mathrm{x}, 10 \mathrm{x}, 20 \mathrm{x}$ and 40x; A: $1064 \mathrm{~nm}, 10 \mathrm{ps}, 50 \mathrm{kHz}, 1,3 \mathrm{~W}(26 \mu \mathrm{J})$; B: $532 \mathrm{~nm}, 7 \mathrm{ps}$, $50 \mathrm{kHz}, 700 \mathrm{~mW}(13 \mu \mathrm{J})$; $\mathrm{C}: 12 \mathrm{~mm}$ glass depth, $355 \mathrm{~nm}, 6 \mathrm{ps}$, $50 \mathrm{kHz}, 400 \mathrm{~mW}(8 \mu \mathrm{J})$, scanning speed $=150 \mathrm{~mm} / \mathrm{s}$, Number of cycles left to right $1 \mathrm{x}, 40 \mathrm{x}, 20 \mathrm{x}, 10 \mathrm{x}$ und $5 \mathrm{x}$.

It can be seen that with decreasing wavelength the depth extension, i.e. the length of the visible laser induced browning tracks, increases. For 1064 and $532 \mathrm{~nm}$ the depth extension nearly matches twice the depth of focus of the used focussing optics in BK7. For soda-lime glass in contrast the depth extension is the fourfold of the depth of focus. At $355 \mathrm{~nm}$ the browning in soda-lime glass was induced completely through the $12 \mathrm{~mm}$ glass depth. Further experiments showed a browning depth at $355 \mathrm{~nm}$ of more than $70 \mathrm{~mm}$. Despite the depth extension was only half of the browning depth in soda lime, comparable results were observed in BK7.

Tab. 1: Laser induced colouring threshold at a pulse density of 5000 per $\mathrm{mm}^{2}$ for (a) BK7 and (b) soda-lime. *: depth extension exceeds sample thickness. **: Sample (Optiwhite ${ }^{*} 80$ x 80 $\mathrm{mm}^{2}$ ) was illuminated from the side edge.

\begin{tabular}{|c|c|c|c|c|}
\hline $\begin{array}{c}\text { Laser } \\
\text { wavelength } \\
\text { and pulse } \\
\text { width }\end{array}$ & $\begin{array}{c}\text { Pulse } \\
\text { Energy } \\
\text { Threshold } \\
(\mu \mathrm{J})\end{array}$ & $\begin{array}{c}\text { Peak } \\
\text { Power } \\
\text { Threshold } \\
\text { (MW) }\end{array}$ & $\begin{array}{c}\text { Peak } \\
\text { Intensity } \\
\text { Threshold } \\
\left(\mathbf{W} / \mathbf{m}^{2}\right)\end{array}$ & $\begin{array}{c}\text { Maximum } \\
\text { browning } \\
\text { depth ex- } \\
\text { tension } \\
\text { (mm) }\end{array}$ \\
\hline & $\begin{array}{l}\text { (a): } 19 \\
\text { (b): } 13 \\
\end{array}$ & $\begin{array}{l}\text { (a): } 1.9 \\
\text { (b): } 1.3 \\
\end{array}$ & & $\begin{array}{l}\text { (a): }<1.5 \\
\text { (b): }<4\end{array}$ \\
\hline $\begin{array}{l}532 \mathrm{~nm} \text { and } \\
7 \mathrm{ps}\end{array}$ & $\begin{array}{l}\text { (a): } 5 \\
\text { (b): } 3 \\
\end{array}$ & $\begin{array}{ll}\text { (a): } & 0.7 \\
\text { (b): } & 0.4 \\
\end{array}$ & $\begin{array}{l}1.4 * 10^{15} \\
8.2 * 10^{14}\end{array}$ & $\begin{array}{l}\text { (a): }<1.5 \\
\text { (b): }<4\end{array}$ \\
\hline $\begin{array}{l}355 \mathrm{~nm} \text { and } \\
6 \mathrm{ps}\end{array}$ & $\begin{array}{l}\text { (a): }<0.5 \\
\text { (b): }<0.3\end{array}$ & $\begin{array}{l}\text { (a): }<0.08 \\
\text { (b): }<0.05\end{array}$ & $\begin{array}{r}<1.6^{*} 10^{14} \\
\quad<1 * 10^{14}\end{array}$ & $\begin{array}{c}\text { (a): }>10^{*} \\
\text { b): }>12^{*} \\
>70^{* *}\end{array}$ \\
\hline $\begin{array}{l}800 \mathrm{~nm} \\
0.1 \mathrm{ps}\end{array}$ & $\begin{array}{l}\text { (a): } 2 \\
\text { (b): } 1\end{array}$ & & $\begin{array}{r}4.1 * 10^{16} \\
2 * 10^{16}\end{array}$ & $\begin{array}{l}\text { (a): }<6 \\
\text { (b): }<10\end{array}$ \\
\hline
\end{tabular}

The spatial resolution in the working plane is wavelength independent and mostly defined by the focus diameter, $20-30 \mu \mathrm{m}$ with the focussing optics used in our experiments.

Tab. 1 compiles the laser induced browning threshold levels for (a) BK7 and (b) soda-lime glass using approx. 5000 pulses per $\mathrm{mm}^{2}$. It also depicts the obtained browning depth extension at maximum single pulse energy in this study: $20 \mu \mathrm{J}$ at $1064 \mathrm{~nm}, 13 \mu \mathrm{J}$ at $532 \mathrm{~nm}$, and $9 \mu \mathrm{J}$ at $355 \mathrm{~nm}$ in the picosecond pulse width range; $100 \mu \mathrm{J}$ at $800 \mathrm{~nm}$ for sub-ps laser pulses.

The transmission spectra of the induced browning bulks in the range of 300 to $1000 \mathrm{~nm}$ for soda lime and BK7 are shown in Fig. 2.

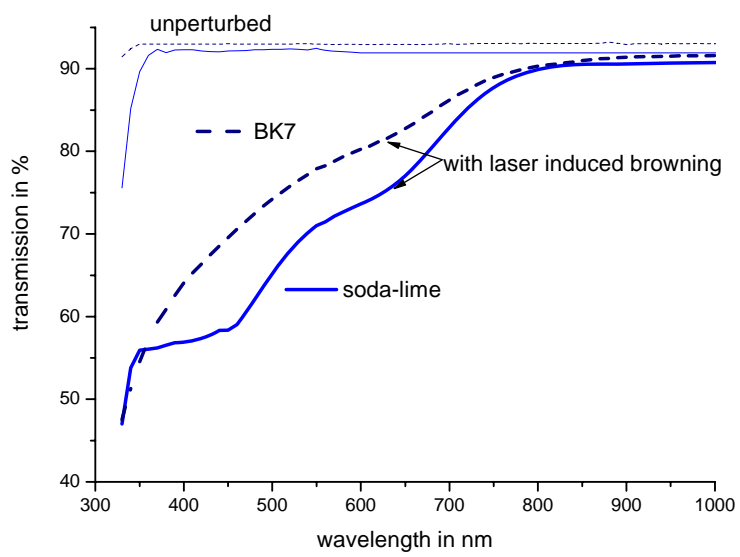

Fig. 2: Transmission spectra of the induced browning bulks for $4 \mathrm{~mm}$ soda-lime (Optiwhite $\left.{ }^{\circledR}\right)$ and BK7 (Schott) after processing with 7 ps laser pulses at $532 \mathrm{~nm}, 50 \mathrm{kHz}, 14 \mu \mathrm{J}$ single pulse energy, $25 \mu \mathrm{m}$ distance between scanning lines and a scanning speed of $250 \mathrm{~mm} / \mathrm{s}$.

The browning was induced at $532 \mathrm{~nm}$ wavelength and 7 ps pulse duration. The single pulse energy was $14 \mu \mathrm{J}$, which equals 3 times of the threshold energy for the browning of the material. Optical light is absorbed in particular in the short wavelength range. The strong absorption in the blue spectral range explains the observed red-brown impression of the colourings. Characteristic for soda-lime glass are the two absorption bands at 400 and $600 \mathrm{~nm}$, which can be related to energetic states of trapped holes and excitons, i.e. colour centres.

The transmission spectrum of the browning in BK7 glass follows a more steady change. At approx. $850 \mathrm{~nm}$ the transmission finally aligns with the undisturbed case in both glasses. Due to the volume dependence of the browning effect, the overall absorption is influenced by the track length and with that a function of the material and the choice of processing parameters.

One way to achieve a variation in bulk colouring is to alter the laser pulse density, which is done by selection of the scanning velocity in the writing process. Another possibility to achieve a similar result is to vary the number of cycles, i.e. repeating the writing process at a constant scanning velocity. Fig. 3 shows that at a continued doubling of the cycle number $(5 \mathrm{x}, 10 \mathrm{x}, 20 \mathrm{x}, 40 \mathrm{x})$ the transmission de- 
creases by an ever-smaller factor, demonstrating a trend to saturation. The same tendency is obtained through scanning velocity bisection, respectively doubling of the pulse density.

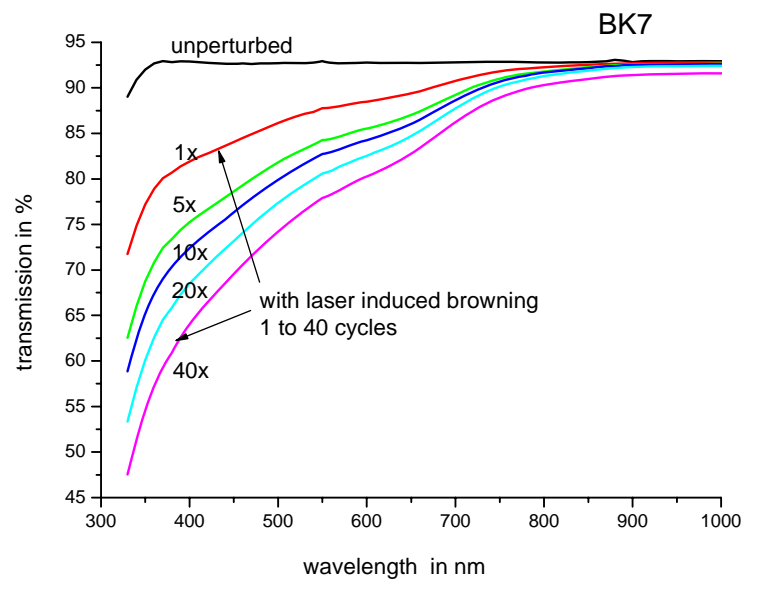

Fig. 3: Transmission spectra of the induced browning bulks for $4 \mathrm{~mm}$ BK7 (Schott) after processing with $7 \mathrm{ps}$ laser pulses at $532 \mathrm{~nm}, 50 \mathrm{kHz}, 14 \mu \mathrm{J}$ single pulse energy, number of cycles $1 \mathrm{x}$ to $40 \mathrm{x}$.

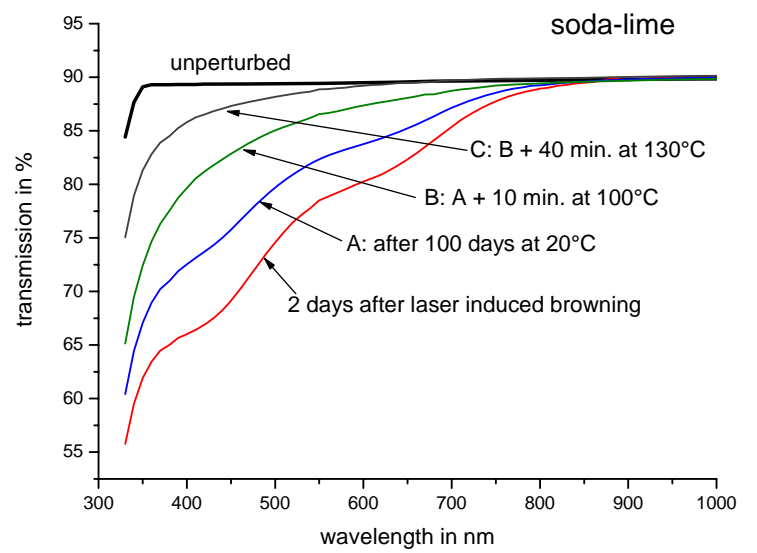

Fig. 4: Transmission spectra of the induced browning bulks for $4 \mathrm{~mm}$ soda-lime (Optiwhite $\left.{ }^{\circledR}\right) 2$ days after processing; A: after 100 days, B: as A, but additionally heating to $100^{\circ} \mathrm{C}$ for $10 \mathrm{~min}$., C: as $\mathrm{B}$, but additionally heating to $130^{\circ} \mathrm{C}$ for $40 \mathrm{~min}$.

The laser induced colouring decreases over time at room temperature, i.e. this modification has no permanent stability. Fig. 4 shows the change in transmission shortly after the processing and 100 days later. This phenomenon is known from radiation-induced defects in glasses, which base on an accumulation of colour centres. The observations of the stability of laser induced colouring in glasses is in strong agreement with results of obtained ionizing radiation. The material dependent bleaching shows an approx. logarithmic temporal behaviour. Even years after processing the browning effect can be observed in some glasses. The effect of heating on the bleaching of the colouring in glasses can also be seen in Fig. 4. Obviously, a temperature dependent recombination process eliminates the defect sites causing the visible browning of glass.

\section{Discussion}

The mechanism and nature of radiation-induced defects of silicate glass has been critically reviewed by many authors [14-16]. Most of these studies are focused on high-purity synthetic samples or sample compositions. One goal was the development of special non-browning glasses used in a reactor or with optical fibres. The recent investigations on laser induced browning with IR femtosecond laser pulses have demonstrated a very similar absorbance characteristic when compared to the results obtained with $\mathrm{X}$-ray radiation [9-11].

The introduction of laser induced colour centres has prompted a renewed interest since they can be potentially utilized for marking applications. The processing time matches industrial requirements in respect to efficiency. A pattern of $20 \times 20 \mathrm{~mm}^{2}$ as seen in Fig. 5 is written in a few seconds. Regarding the depth extension, even the generation of 3D-patterns is possible. The choice of pulse energy, pulse density and cycle number influences the intensity of the browning, e.g. for increasing the readability over a longer period.

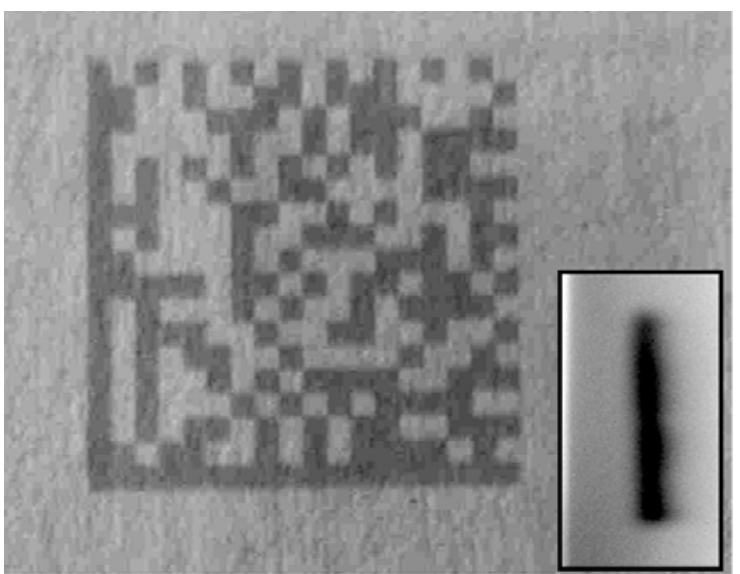

Fig. 5: Possible marking application of ps laser induced stressfree browning. 2D-Barcode $\left(20 \times 20 \times 4 \mathrm{~mm}^{3}\right)$ inside a $12 \mathrm{~mm}$ soda-lime glass (Optiwhite $\left.{ }^{\circledR}\right)$. Left: front view, right: side view (depth extension). Processing parameters: $532 \mathrm{~nm}, 7 \mathrm{ps}, 50 \mathrm{kHz}$, $10 \mu \mathrm{J}$.

Next to certain important laser parameters, such as pulse width and wavelength, the focusing alignment into the glass is crucial for obtaining the browning effect without laser induced density changes. Based on studies performed with $0.1 \mathrm{ps}$ at $800 \mathrm{~nm}$, the energy per volume threshold for modest density changes, observed as alteration in the refractive index, lies above $40 \mathrm{~J} / \mathrm{mm}^{3}$ [17]. Following estimation is performed to determine the maximum volume energy density: the pulse energy is divided by the volume of the visible laser induced colouring track. Two "worst case" maximum volume fluence scenarios are presented: A) picosecond pulse excitation at $1064 \mathrm{~nm}$ : track length and diameter equals $1.5 \mathrm{~mm}$ and $0.025 \mathrm{~mm}$, yielding a volume of $0.74 \times 10^{-3} \mathrm{~mm}^{3}$. The single pulse energy is $20 \mu \mathrm{J}$, which leads to a volume fluence below $30 \mathrm{~mJ} / \mathrm{mm}^{3}$; B) femtosecond pulse excitation at $800 \mathrm{~nm}$ : track length and diameter equals $6 \mathrm{~mm}$ and $0.035 \mathrm{~mm}$, yielding a volume of $5.8 \times 10^{-3} \mathrm{~mm}^{3}$. The single pulse energy is $100 \mu \mathrm{J}$, which leads to a volume fluence below $20 \mathrm{~mJ} / \mathrm{mm}^{3}$. 
The estimated volume fluence values for laser induced colouring are several orders of magnitude lower than for the density change reported in [17]. One can also account the fluence values expressed in energy per $\mathrm{cm}^{2}$, as typically discussed for laser-surface interactions. This then yields ca. $4 \mathrm{~J} / \mathrm{cm}^{2}$ in case A) and even $10 \mathrm{~J} / \mathrm{cm}^{2}$ in case B). Indeed, the femtosecond pulses at $10 \mathrm{~J} / \mathrm{cm}^{2}$ focused on the glass entrance surface would actually damage the sample as expected [6,7]. And perhaps even more surprising, picosecond UV laser pulses at $8 \mu \mathrm{J}$ can easily be utilised for the surface machining of the studied transparent samples under the experimental conditions outlined in this paper, if focused on the surface. However, the laser pulses are focused several mm inside the bulk: no density changes were observed with picosecond UV laser pulses even at a very slow scanning speed $<<1 \mu \mathrm{m} /$ pulse, i.e. high pulse-to-pulse overlap. The colouring starts at the surface and can extends throughout the sample over several $\mathrm{mm}$. Quite opposite, the generation of "micro-dots" is imposed inside the laser coloured volume using picosecond laser pulses at 1064 and $532 \mathrm{~nm}$ at similar focusing alignment. Possible reason for the observed wavelength dependence in the generation of density changes is the significant difference in the depth extension of the colouring. The browning for UV picosecond pulses can extend over several $10 \mathrm{~mm}$, indicative for a photon energy distribution over a large volume.

It is not clear if colour centre formation can be characterized as the precursor for the more irreversible material reaction mechanisms yielding density changes, which in top view resemble "micro dots". An example for array of „micro dot" formation is depicted in Fig. 6. Both samples were processed under identical condition, except for the scanning velocity. At an overlap of $1 \mu \mathrm{m} /$ pulse, the coloured volume also demonstrates a grating pattern of localized micro density changes. This effect presented for BK7 in Fig. 6 was observed only at 1064 and $532 \mathrm{~nm}$. It seems, that in the picosecond case of $355 \mathrm{~nm}$, the excitation is far less localized. Laser excitation is less confined, so that bulk browning without inducing additional density defects is much more likely, providing the basis for practically stress -free markings.

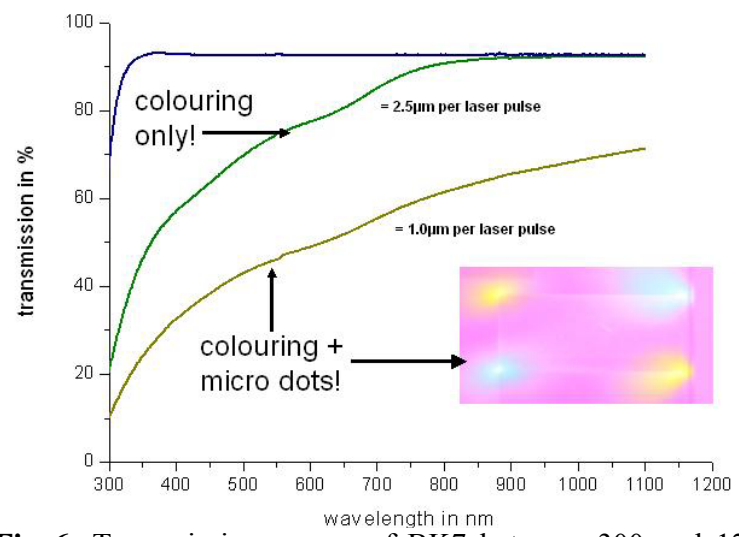

Fig. 6: Transmission curves of $\mathrm{BK} 7$ between 300 and $1200 \mathrm{~nm}$ taken directly after ps laser excitation at $532 \mathrm{~nm}$, comparing scanning speed of $2.5 \mu \mathrm{m} /$ pulse (top curve) and $1 \mu \mathrm{m} /$ pulse (lower curve). In the latter, the microscope and polariscope analysis (inset) uncover the additional development of density centres inside the colourized volume.
All the results reported in this paper are evident as long as the focusing strength remains modest, i.e. focal length $\geq 80 \mathrm{~mm}$. The transition of laser induced browning, typically addressed as ionization effect, and generation of density changes, commonly referred as a thermal process, is quite attractive and subject of ongoing studies. In addition, the high efficiency of colour centre formation during picosecond excitation at $355 \mathrm{~nm}$ for BK7 and soda lime glass is to some degree fairly uncertain and remains under investigation.

Laser induced colour centres may remain stable for several years at usual room temperatures and daylight conditions. If required, they can be erased easily by heating the material. Obviously, the recombination of the induced excitons can be significantly accelerated by heating the glass samples to temperatures of $\mathrm{T} \geq 100^{\circ} \mathrm{C}$.

The decrease in the number of excitonic states, and thus of the browning, is material specific for any given start intensity. The temporal change in intensity and thus in the transmission curve can be used for example as a measure for the proper storing of medical products.

\section{Conclusion and Summary}

The possibility of generating picosecond laser induced colour centres inside silicate glasses, such as BK7 and soda-lime (Optiwhite $\AA$ ), is demonstrated. The colour centres absorb visible light, especially in the shortwavelength regime. Absorption characteristics as well as time dependent bleaching of laser induced browning are in alignment with known characteristics from $\mathrm{X}$-ray radiation induced browning.

The transition from colouring to a formation of density changes, „micro dots“, at a material dependent laser pulse energy density could be an advantage for several applications. Fig. 7 shows an example for a „micro dot"grating, generated with ps pulses. It is planed to further examine and optimize the micro-dot size in an upcoming research project in cooperation with the Max-Born-Institute in Berlin.

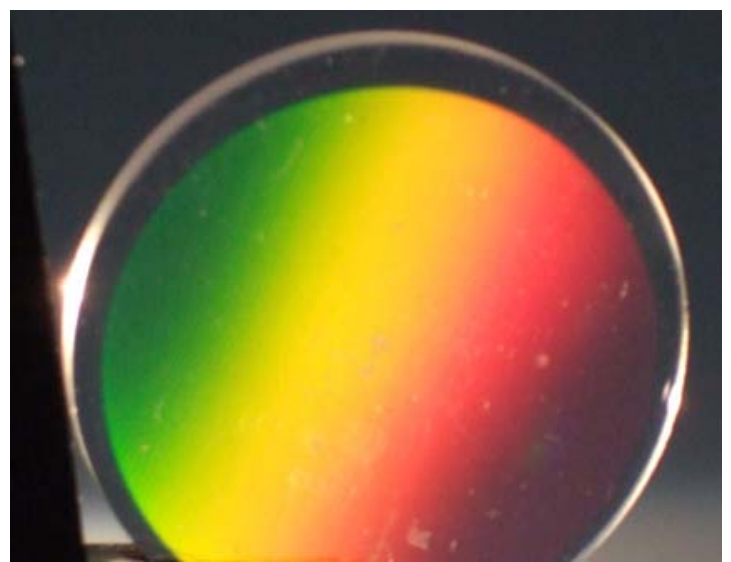

Fig. 7: Example for a „micro dot"-grating inside a sapphire sample with the typical rainbow coloured light diffraction; green (left), yellow (middle), red (right).

Another important aspect of this study is the choice of guiding optics, e.g. BK7 lenses, for energetic ps laser pulses, where laser browning is to be avoided. As demonstrated, optical material such as BK7 may not be 
first choice even at a wavelength of 532 or $1064 \mathrm{~nm}$. Laser induced browning of the optical components can occur at a moderate small beam diameter, considering multi-pulse irradiation at energetic picosecond laser pulses of $>100 \mu \mathrm{J}$. There is a need to address this problem in the optical design of e.g. trepanning systems for high-power industrial picosecond laser systems developed for machining [18].

\section{Acknowledgement}

The authors gratefully acknowledge the financial support by the federal BMWi in a national $\mathrm{AiF} / \mathrm{IGF}$ project $14982 N$. In addition, many thanks are expressed to Hans Joachim Eichler and Uwe Bindig for their help.

\section{References}

[1] J. Sheng et al., Journal of Non-Crystalline Solids 352, 2914-2916 (2006).

[2] K. Miura et al., SPIE Proc. 3618, 141, 1999.

[3] A.M. Streltsow et al., Opt. Lett. 26, 2001.

[4] J.D. Mills, P.G. Kazansky, and E. Bricchi, Appl. Phys. Lett. 81, 2, 196, 2002.

[5] L. Sudrie, M. Franco, B. Prade, A. Mysyrowicz, Opt. Comm. 171, 279-284, 1999.

[6] D. Ashkenasi, A. Rosenfeld, S. Spaniol, A. Terenji, SPIE Proc. 4978, 180-187, 2003.

[7] E.E.B. Campbell, D. Ashkenasi, A. Rosenfeld, Lasers in Materials Science (Trans Tech Publications, Switzerland, 1999), pp. 123-144, 1997.

[8] B.C. Stuart, M.D. Feit, A.M. Rubenchik, B.W. Shore, M. D. Perry, Phys. Rev. Lett. 74, pp. 2248, 1995.
[9] A.-C. Tien, S. Backus, H. Kapteyn, M. Murnane, G. Mourou, Phys. Rev. Lett. 82, pp. 3883, 1999.

[10] O.M. Efimov, K. Gabel, S.V. Garnov, L.B. Glebov, S. Grantham, M. Richardson, and M.J. Soileau: Color center generation in silicate glasses exposed to infrared femtosecond pulses, J. Opt. Soc. Am. B, Vol. 15, 1, 193-199, 1998.

[11] J.B. Lonzaga, S.M. Avanesyan, S.C. Langford, and J.T. Dickinson: Color center formation in soda-lime glass with femtosecond laser pulses, J. Appl. Phys. 94, 7, 4332-4340, 2003.

[12]D. Ashkenasi, H. Varel, A. Rosenfeld, S. Henz, J. Herrmann, E. Campbell, Appl. Phys. Lett. 72, 12, pp. 1442, 1998.

[13]D. Ashkenasi, H.J. Hoffmann, D. Krause, G. Müller, SPIE Proc. 4977, 2003.

[14]D. Ashkenasi, H.J. Hoffmann, G. Müller, SPIE Proc. 5063, 92-102, 2003.

[15]D.L. Griscom, Nature of defects and defect generation in optical glasses, SPIE Proc. 541, 38-59, 1985.

[16] A. Holmes-Siedle and L. Adams, Handbook of radiation effects (Oxford University Press, Oxford, 1993)

[17] Y. Jee, M.F. Becker, R.M. Walser, J. Opt. Soc. Am B 5, pp. 648, 1988.

[18] D. Ashkenasi, N. Mueller, T. Kaszemeikat, G. Illing, Avanced laser micro machining using a novel trepanning system, Proceedings of the LPM 2010, to be published.

(Received: June 7, 2010, Accepted: January 28, 2011) 